\title{
CrimRxiv
}

\section{Another Digital Divide: Cybersecurity in Indigenous Communities}

\section{Laura Huey, Lorna Ferguson}

Published on: Feb 28, 2022

DOI: $10.21428 / c b 6 a b 371 . b b f 05 c b c$

License: Creative Commons Attribution 4.0 International License (CC-BY 4.0). 


\section{Abstract:}

The Indigenous 'digital divide' relates to community-level disparities in access and use of online technologies, a prominent public policy issue that federal governments have attempted to address. Following from such efforts is an expected increase in communication and other technologies. However, concurrently, cybersecurity becomes a matter warranting consideration, as increased access means increased exposure to online harms for which many Indigenous communities may lack awareness, education, and prevention skills. To offer key insights relevant to this matter, this study conducted a systematic review of research pertaining to Indigeneity and cybersecurity issues. Findings show that critical subject areas, such as human trafficking and cyberbullying, are starkly under-researched and small in study volume. It was also discovered that there is very little diversity in research topics, rendering the research base narrow in scope. From these findings, this study concludes with several critical areas for future research and evaluation, as is necessary for public policy and prevention-oriented initiatives.

Keywords: digital divide, cybersecurity, cybercrime, cyberharms, Indigenous communities, online technologies, policing, policy studies

This is a pre-copyedited, author-produced version of an article published in Sociology Publications. The version of record, Huey, L., \& Ferguson, L. (2022). Another Digital Divide: Cybersecurity in Indigenous Communities. Sociology Publications, is available online at https://ir.lib.uwo.ca/sociologypub/55/. When citing, please cite the version of record.

\section{Introduction}

The term 'digital divide' has been used to highlight community-level disparities in access and use of online technologies. Those disparities are particularly acute in Canada's northern rural and remote regions, which may lack access to broadband or cellular services (Howard, Busch and Sheets 2010; McMahon 2011; Government of Canada 2021). Disparities also emerge when looking at access issues among socioeconomic groups in urban and other areas, with lower-income citizens less likely 
to have Internet access due to cost, reporting access through lower download speeds, and expressing worries over the ability to pay for Internet usage (Andrey, Masoodi, Malli and Morkenoo 2021). These inequities raise the issue of digital illiteracy, leading scholars to assert that lack of access to technology, software, broadband, and cellular facilities results in an inability to learn technical skills useful in today's employment market, thus further exacerbating income and other inequalities (Howard et al. 2010). Another significant concern, especially relevant for rural, remote, and impoverished communities, is the increasing necessity of broadband technology for community development (McMahon 2011), as well as access to healthcare, education, purchasing foods, and goods, maintaining family and social connections, and a host of other activities (Toth, Smith and Giroux 2018).

There is, however, another aspect of the digital divide phenomenon that merits research and policy attention. Increased exposure to online activities can come with costs in the form of increased cyber-security risks and the potential for victimization. Although, in theory, anyone can be a victim of cybercrime, the reality is that online harms are not borne equally across all demographic groups (Holt and Bossler 2008; Powell and Henry 2019; Whitty 2020). While much of the research literature in this area has focused on the digital divide as a generational issue, with younger demographic groups seen as being more technologically savvy and thus less prone to some forms of cybervictimization (Debb, Schaffer, and Colson 2020), we argue for a more diverse approach to understanding the relative risk of online harm, the strengths and limitations of current prevention methods for different ethnic and other groups, and the need for an improved understanding of how to foster culturally appropriate forms of cyber-resiliency. To that end, the goal of this policy brief is to begin the process of addressing these deficits through a systematic review of the relevant Canadian research on cybersecurity issues affecting Canada's Indigenous communities.

\section{The Indigenous Digital Divide}

Writing in 2010, Howard and colleagues observed that Canada's digital divide was borne of Canada's unique geography, history, and culture(s). These factors, singly and in combination, resulted in sizeable knowledge gaps for Indigenous Canadians, particularly those in rural and remote communities which had yet to receive the infrastructure required for broadband and federal subsidies to encourage its use. As modern societies grow ever-increasingly dependent on the online world for social contact, educational opportunities, health information, consuming goods and services, 
among other routine daily activities, the negative consequences of such knowledge gaps cannot be understated. Foremost among them, however, is the fact that

the digital divide exacerbates inequality by limiting yet another avenue for participation in the economy. Not only are communities that lack the Internet excluded from the nationwide online economy, but they also miss out on the social and human capital that flows online, from job training and employment opportunities to civic organization, news, and cultural content (Howard et al. 2010: 116).

It is essential to acknowledge that, by 2010, the lack of Indigenous access to the 'information superhighway' had long been recognized as a prominent public policy issue, one that successive federal governments had attempted to address through initiatives aimed at connecting communities through central access points - such as schools and community centres (Kimery and Amirkhalkhali 2011; Toth et al. 2018). Provincial and regional governments were also attempting to address this matter. In 2008, the Kativik Regional Government brokered an agreement with Telesat Canada to provide satellite coverage for broadband use to remote communities in the Arctic regions of Quebec, Nunavut, Manitoba, and Ontario (Hamel, Benyoucef, and Kuziemsky 2012). Local communities have also developed innovative approaches to providing cellular and broadband to residents (O’Donnell et al. 2011; Beaton, Linden, and O’Donnell 2015). Despite such efforts, by 2019, Canada's Canadian RadioTelevision and Telecommunications (CRTC) Board was reporting that first nations communities were still lagging behind other communities in their ability to access the Internet through broadband, with only 31.3\% having access (CRTC 2019) (see Figure 1 below). As of 2019, they note, broadband was "not accessible to First Nations reserves in Saskatchewan, Newfoundland and Labrador, Yukon, and Northwest Territories" (ibid.: 280). It is worth noting that cellular reception in many of these same areas is problematic or has been non-existent (Beaton et al. 2015; Rogers 2018). Therefore, we cannot assume that Indigenous persons living in urban areas have access to cellularbased mobile technologies. Studies of impoverished Indigenous residents of major cities suggest low rates of mobile connectivity (Jongbloed et al. 2020), and both age and socioeconomic factors such as income, education, and employment have been found to significantly influence Indigenous use of the Internet across Canada (AliHassan, Eloulabi and Keethakumar 2020).

\section{Figure 1. Broadband Internet Availability, 2018}




\section{8}

\section{Broadband Internet} service availability for various communities
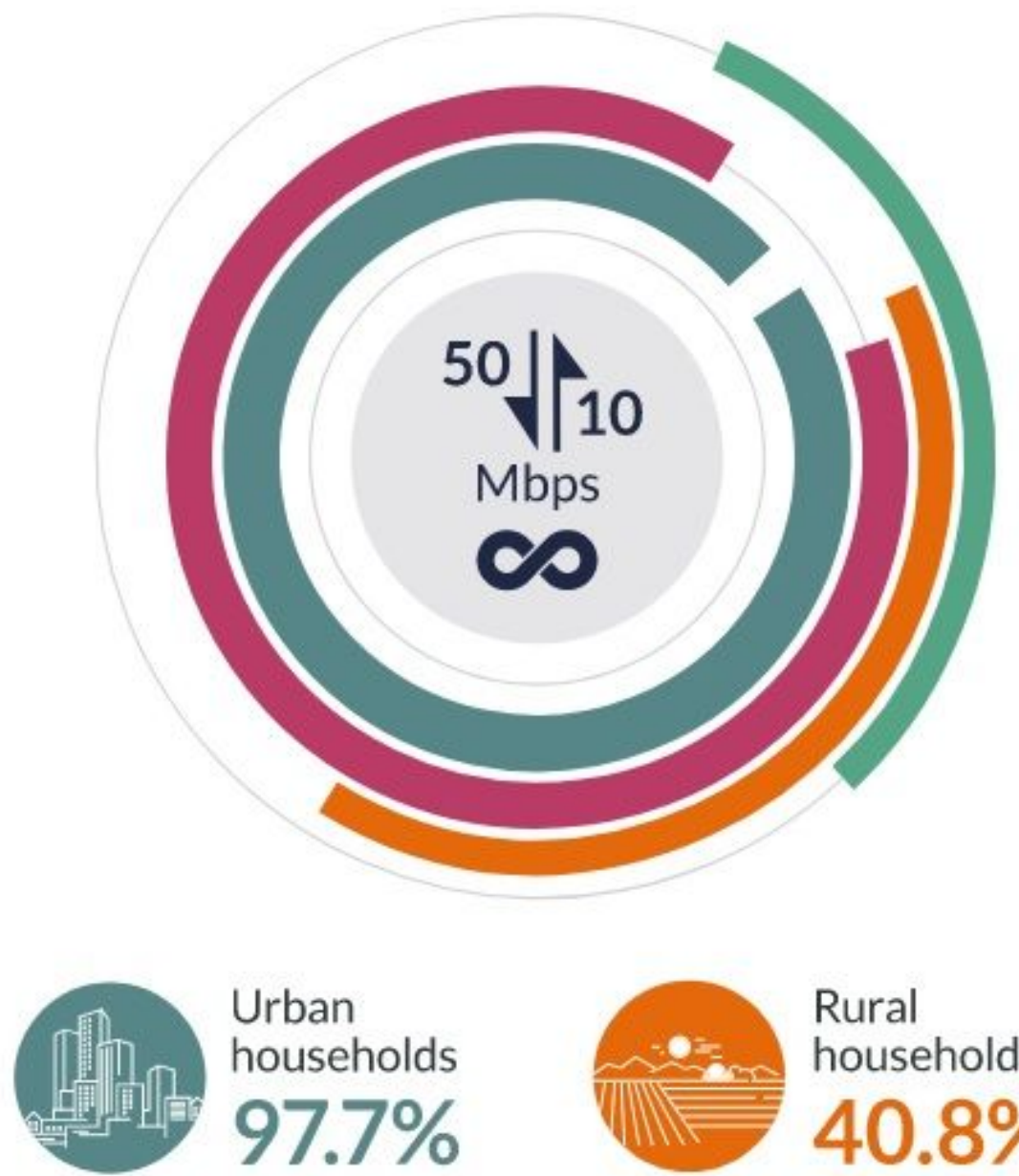

Urban households $97.7 \%$
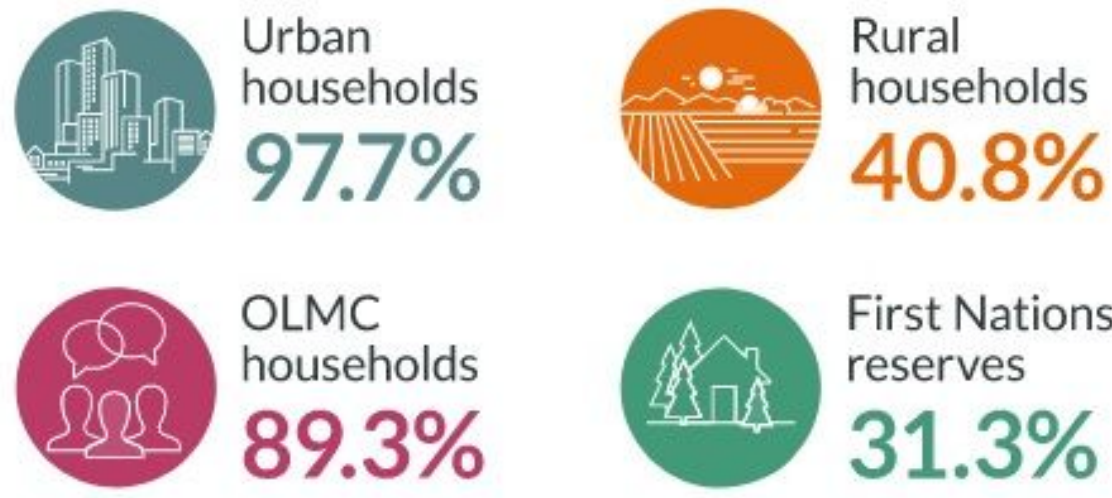

First Nations reserves

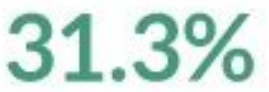

\section{Chart, sunburst chart Description automatically generated}

Source: CRTC (2019: 279). 
One might reasonably ask why cybersecurity is a pressing policy issue for a population with - relative to other groups - low rates of Internet connectivity. A study conducted in 2000 found that Indigenous citizens with access to technology and software were equally as likely to engage in online activities as other demographic groups (Kimery and Amirkhalkhali 2011). Subsequent research shows diverse use patterns - from accessing healthcare information to maintaining social connections to supporting community activism and engaging in cultural activities (ibid.; Gaertner 2015; Wilson and Zheng 2021). In other words, we can and should expect that once communication and other technologies are made more readily available, there will be significant community uptake and engagement. The benefits of access and engagement are innumerable, including a host of social, economic, educational, and other positive outcomes. However, with increased access also comes increased exposure to online harms for which many communities may lack awareness, education, and prevention skills (see Staksrud, Ólafsson and Livingstone 2013). It also means that cybersecurity experts need to be prepared to develop culturally appropriate methods for fostering cyber-crime prevention and cyber-resiliency, areas which - as we document below have generated little attention to date.

\section{Method of Inquiry}

The research conducted for this study seeks to answer three essential questions:

RQ1: What is the nature and scope of Canadian research on cybersecurity-related issues (harms, responses, and prevention) affecting Indigenous communities as represented within the published, peer-reviewed literature over the past 20 years (2001-2021)?

RQ2: What is the nature and scope of Canadian research on these same issues as represented within the 'grey literature' over the past 20 years (2001-2021)?

RQ3: How can this literature inform response and prevention efforts moving forward?

\section{Systematic Literature Review}

To address the research questions above, we chose to conduct a systematic literature review to synthesize the studies' results to construct an overall picture of the relevant research in the area. The decision to take this approach was made due to the quality and quantity of literature available. As we describe in further detail in the findings section below, we were only able to locate thirteen $(n=13)$ studies that met the search 
criteria and, in some cases, the focus of the study was, as an example, 'experiences of children aged 13-17' rather than exclusively on 'experiences of Indigenous children aged 13-17.' Indeed, in one of the included studies, we could only identify a single instance of the researchers citing interview data from an Indigenous participant; however, we opted to keep this in our dataset due to the lack of qualifying studies. Another reason for adopting this particular approach was that the final dataset included a mix of quantitative and qualitative work. Further, the types of quantitative analysis used in the included studies meant that meta-analysis of, say, the effect sizes of cyberbullying prevention programs would not be possible.

The current systematic literature review differs from conventional narrative approaches because the latter is often described pejoratively in research circles as 'cherry picking' in that no attempt is made to identify and eliminate biases in the searching and use of materials collected (Xiao and Watson 2019). By way of contrast, a systematic literature review entails employing carefully developed search strategies to locate relevant research, which is then typically appraised for rigor and utility before being coded and synthesized. The goal of the latter is to produce literature reviews that are, in essence, "scientific inquiries" and thus "valid, reliable and repeatable" (Xiao and Watson 2019: 93). This is not to suggest this approach is without limitations, but rather to emphasize the need for researchers to reduce bias and produce scholarly output that others can replicate - two fundamental hallmarks of the scientific method.

\section{Search Strategy}

Recognizing the possibility that there may not be a significant pool of research in this area, and thus the net should be cast as widely as possible to maximize results, the first decision was to search for both peer-reviewed and 'grey' literature. Concerning the former, we utilized a university search engine to search academic databases available at the University of Western Ontario, including JSTOR, PubMed, Google Scholar, Sociological Abstracts, among others. To identify relevant examples of grey literature, we began with searches of our university's databases, including numerous dissertations and theses sites and databases storing government reports. Then, we repeated our searches using the Google search engine to ensure we unintentionally omitted as few studies as possible.

The second decision made was to set an appropriate search period. Home computers became increasingly popular throughout the 1990s. In addition, throughout much of this decade, Internet access was gained through dial-up connections, with commercial 
broadband only becoming available in the late 1990s. As a result, the decision was made to set the search criteria to begin at 2000 with an end date of December 2020.

In advance of beginning searches, we also had to create a list of search terms that would allow us to collect studies of topics that encompass the three major themes of this work: 'cyberharms,' 'cyber-responses,' and 'cyber-prevention.' In doing so, we also had to factor in changes in terminology that occurred over that time. For example, in the early part of the millennium, the term 'aboriginal' was still widely in use; however, by 2020 , the accepted term became 'Indigenous.' Thus, we began with general search terms such as 'Indigenous internet victimization' and 'Indigenous cyber crime,' before substituting words such as 'aboriginal' and 'first nations.' 'Cyber' was similarly replaced with' online,' 'Internet,' and 'social media.' When we reached a point at which it was clear these general searches would yield no further results, we then looked more narrowly at specific types of online activities, such as 'harassment,' 'bullying,' 'fraud,' and 'human trafficking,' among others. When this again failed to yield many more results, we went through each of the papers that met our search criteria and began tracing relevant references to see if we had missed any other papers.

\section{Inclusion and Exclusion Criteria}

This paper aims to provide a detailed overview of the central findings of Canadian scholars working in or near the intersections of Indigeneity and cybersecurity issues. We hope that such an overview can inform policy and, in particular, guide future research development by identifying the strengths and weaknesses of the existing evidence base. To that end, we decided to focus on locating pieces of primary research, including a range of inclusion and exclusion criteria to meet these goals. Figure 2 offers a depiction of these conditions.

\section{Figure 2. Visual Presentation of the Inclusion and Exclusion Criteria}




\section{Inclusion Criteria}

- Contains the results of a research study.

- Contains a clear description of the methodology used.

- Provides information on one or more aspects of cybersecurity issues facing Indigenous communities.

- Utilizes Canadian data.

\section{Exclusion Criteria}

- Does not include a piece of primary research (i.e., was a legal analysis, opinion piece, commentary, or introduction).

- Contains no discussion of research methodology.

- Inability to access paper.

With these criteria in place, each resulting abstract returned from online searches was read, and a determination was made to include or exclude the paper. For those situations in which it was unclear from the abstract whether a paper was suitable, the paper was downloaded and read in its entirety. The outcome of these processes and, therefore, the final sample is thirteen papers $(n=13)$.

\section{Coding and Analysis}

To answer each of the research questions above, we began by employing a simple inductive coding scheme using the following categories: title, first author, year of publication, approach (quantitative, qualitative, or mixed methods), methodology (data collection and analysis techniques), and data source. We then created separate codes for each relevant topic and sub-topic covered in the paper/report under the three selected themes: cyberharms, cyber-responses, and cyber-prevention. From here, we structured our response to the third research question by abstracting relevant content from each article and using it to construct a narrative synthesis. This approach aimed to provide information on what is and is not known based on this literature and what future directions we might take from a policy or research perspective.

\section{Findings}

In this section, we attempt to accomplish two goals. The first is providing an overview of the extent and scope of the research literature in this area, focusing on the volume 
and scope of topics contained within. The second goal is to describe the main findings of the research collected related to the three major themes explored: cyberharms, responses to cybercrime, and prevention efforts.

\section{Overall View}

Although our search criteria specified a range of 2000 to 2021, we could locate no relevant journal articles, government reports, theses, or dissertations before 2011. Thus, as shown in Figure 3 below, we started listing article counts from 2011 onwards. In doing so, we see that interest in issues related to Indigeneity and cybersecurity generated little scholarly interest prior to 2017.

Figure 3. Year and Number of Works Located, 2011-2021

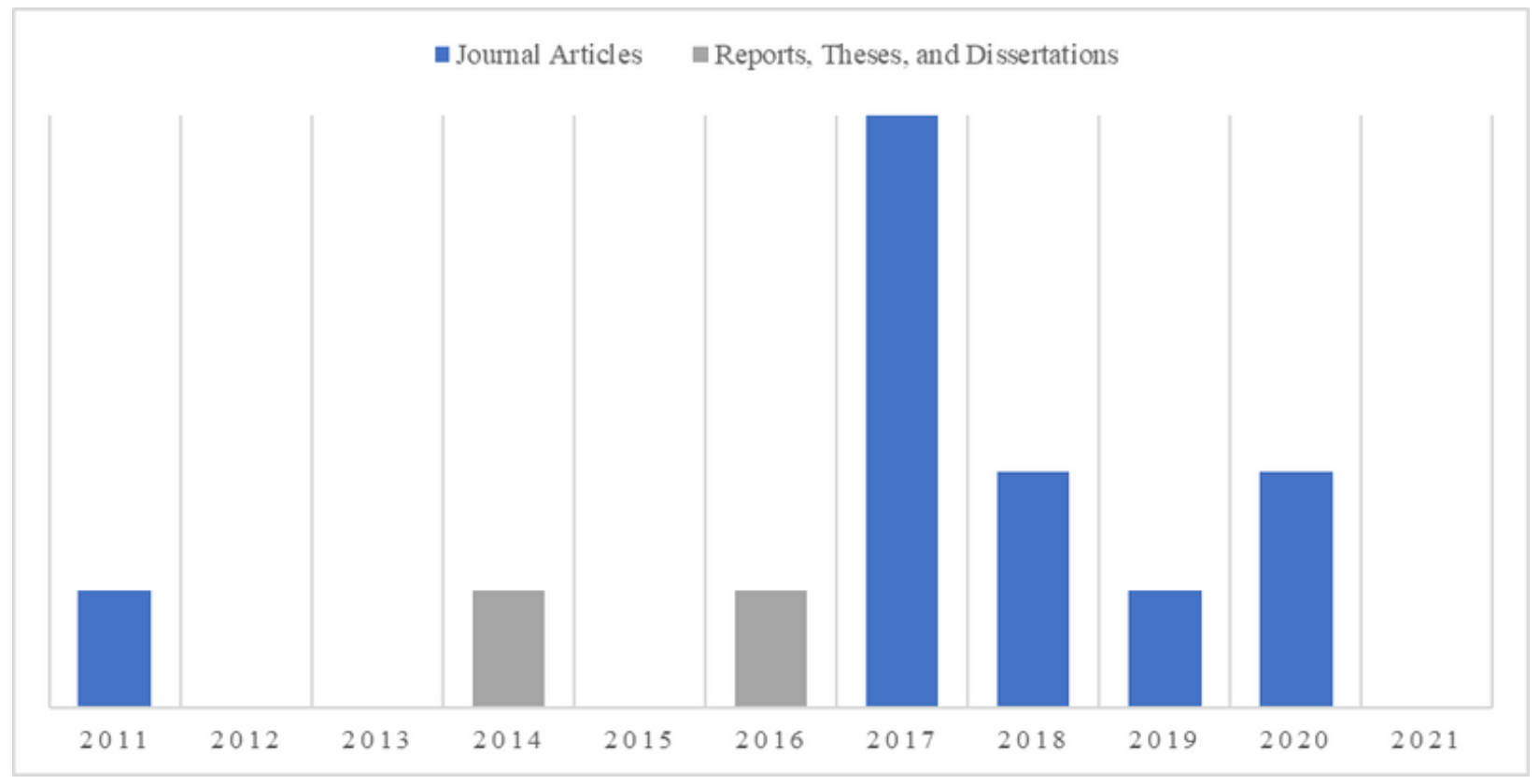

We also looked at research methods and data sources to provide a view of the types of research conducted, as can be seen in Table 1. The majority were qualitative in the approach, consisting of interviews conducted by the researchers themselves. Two further studies relied on content analysis of online discussions and government reports (one identified below as part of a mixed-methods study). Five $(n=5)$ of the studies were quantitative, and each drew on survey data. Three $(n=3)$ of these were studies in which the survey was conducted by the author(s); the other two (n-2) relied on existing datasets, one from Statistics Canada, the other from a national level health study of gay and bisexual men. 
Table 1. Methods Employed

\begin{tabular}{|c|c|}
\hline Methodology & $\mathbf{n}$ \\
\hline \multicolumn{2}{|l|}{ Quantitative } \\
\hline Survey & 5 \\
\hline Existing dataset & 1 \\
\hline File review & 0 \\
\hline Experimental & 0 \\
\hline \multicolumn{2}{|l|}{ Qualitative } \\
\hline Interviews & 5 \\
\hline Content analysis & 1 \\
\hline Focus groups & 0 \\
\hline Experimental & 0 \\
\hline \multicolumn{2}{|l|}{ Mixed methods } \\
\hline Interviews & 2 \\
\hline Survey & 2 \\
\hline Content analysis & 1 \\
\hline Focus groups & 1 \\
\hline
\end{tabular}

\section{Cyberharms}

Three major classes of cyberharms were identified in reviewing this literature. These were: online harassment of adults, human trafficking of women and girls through online sources, and cyberbullying 1 of Indigenous children and youth. Table 2 reflects the number of studies for each $\underline{2}$.

Table 2. Papers Focusing on Cyberharms 


\begin{tabular}{|l|l|}
\hline Topic & n \\
\hline Online harassment & 2 \\
\hline Human trafficking & 4 \\
\hline Cyberbullying & 6 \\
\hline
\end{tabular}

\section{Online Harassment}

Unfortunately, we could locate no research focusing exclusively on the experiences of online harassment of Indigenous citizens. However, we were able to locate two studies referencing online harassment of Indigenous women. The first was a study by Hill and Johnson (2020) on online interpersonal victimization against women, in which they relied on Statistics Canada data to examine the extent to which women face online threats and intimidation, among other forms of harassment. Drawing from a sample of over 28,000 survey participants - both men and women -

who had had one or more experiences of this type of harassment, they parsed out specific factors that increased the likelihood of being a victim of this form of cyberharm. These factors include Indigenous identity, aged 15 to 34, single status, some form of physical or psychological impairment, and having been without a residence or precariously housed (ibid.).

The second paper in this area was a study of online harassment of Canadian politicians (Wagner 2020). This qualitative study drew on interview data from 101 politicians and potential political candidates, including an unknown number of Indigenous citizens. Only one, a non-candidate with political experience, is explicitly cited as having direct experience: "'They never say, 'You know, I really disagree with how you voted on that bill.' It's 'You're fat so what do you know?' or 'You're a dyke, what do you know?' or 'You're Indian, what do you know?'” (ibid.: 9).

\section{Human Trafficking}

Four of the articles we located examined the issue of online human trafficking of women and girls. The most directly relevant were two papers by Louie $(2017,2018)$ from his Ph.D. dissertation work on anti-trafficking prevention for Indigenous girls. The first draws on interviews with survivors of sexual exploitation and representatives from anti-trafficking groups to explore traffickers' use of social media to target vulnerable girls. Louie finds that in the early to mid-part of the 2010s, social media 
platforms - in particular Facebook - are used to identify and target girls in reserve communities with the goal of luring them off-reserve (Louie 2017). A tactic frequently used by traffickers is 'love bombing' - using romantic pretenses to overwhelm and thus manipulate vulnerable girls (ibid.). Not only does Facebook provide opportunities for traffickers to identify girls within extended friend networks, but it also serves as a communication tool through which traffickers can set girls up on 'dates,' thus keeping them out off the streets and out of sight from police and other possible intervenors (ibid.). The second paper from Louie looks more widely at avenues for sexual exploitation of Indigenous women and girls, of which social media is one (Louie 2018). Of the two, the first provides significantly more detail on the process of Internet-based recruitment, whereas the second provides possible means of combatting this phenomenon.

Two other papers are clustered under the 'human trafficking' theme: a M.A. thesis by Turkington (2020) and a report for Public Safety Canada by Boyer and Kampouris (2014). In the former, data collected from web-based sources (i.e., government reports) is supplemented with interviews with individuals from anti-trafficking organizations to explore how women and girls from Indigenous communities in Western Canada are lured into human trafficking in urban centres (ibid.). Turkington's (2020) respondents suggest a significant contributor to this process is the proliferation of Internet-based platforms and applications (apps), which render it much easier to locate and contact potential victims. This view is also shared by interviewees cited in a more extensive qualitative study of human trafficking within Indigenous communities conducted by Boyer and Kampouris (2014). Historically, all aspects of sex work took place in physical spaces, often referred to as 'tracks' or 'strolls.' According to police officers cited by in this study, today the Internet offers an unlimited number of 'virtual tracks,' increasing not only recruitment opportunities, but also solicitation and exploitation (ibid.). As in the Louie (2017) study, respondents identify Facebook as a standard tool for traffickers and observe the use of gaming sites as other spaces for recruiting potential victims. Although the authors never specify the site, they do note the existence of at least one website "specifically targeted to the trafficking of Aboriginal women and girls" (ibid.: 24), and several study participants noted the presence of profiles of Indigenous women in advertisements for sex work on online classified pages (ibid.). While some interviewees felt that the number of Indigenous profiles was low, the authors note writing in 2014 - that the lack of access to the online world has tended to insulate women and girls in more northern communities from Internet-based sexual exploitation (ibid.). 


\section{Cyberbullying}

The most frequent cyberharm studied by researchers in the literature we collected was cyberbullying $(n=6)$. The focus of five $(n=5)$ of these articles was on cyberbullying of Indigenous children and youth; one $(n=1)$ was on cyberbullying of gay and bisexual adult men.

Concerning children and youth, the earliest study to appear was in 2011 by Lemstra and colleagues. Drawing on survey data collected from children and youth aged ten to sixteen attending schools under the authority of the Saskatoon Tribal Council, these researchers explored the extent to which Indigenous young people living 'on reserve' were subjected to different forms of physical, verbal, and other forms of bullying. Among the 204 surveys completed, they found that $30.3 \%$ of respondents had been subjected to cyberbullying on at least one occasion in the preceding four weeks (ibid.). In comparing all rates of bullying experienced by surveyed youth, Lemstra et al. (2011: 465) observed that Indigenous children and youth on reserve experienced rates "higher than the national average." They further noted that "irrespective of the type of bullying, [Indigenous] youth who were bullied were at least twice as likely to suffer from depressed mood" (ibid.: 465).

Another study focusing on children in Saskatoon looked at rates of cybervictimization among all young people aged nine to fourteen (Mobin, Feng, and Neudorf 2017). Analyzing survey data from a sample of 5,783 students in grades five to eight, researchers discovered that one of the risk factors for cyberbullying with Indigeneity. As they explain, "we found that Aboriginal students are at a higher risk of being cyberbullied compared to non-Aboriginal students. This phenomenon may be attributable to power differentials across social groups with roots in intergenerational trauma and the after-effects of colonialism" (ibid.: e479).

The link between cybervictimization and mental health issues among Indigenous victims of cyberbullying has also been explored by Broll and colleagues (2018). In a survey of 170 Indigenous youth from 3 different provinces and territories, these scholars found that $17.3 \%$ of their participants had been subject to cyberbullying and that both bullying and cyberbullying contribute significantly to adolescents' depression, anxiety, and general stress (ibid.). They also observed that, based on their results, "bullying and cyberbullying victimization and perpetration are prevalent among Indigenous adolescents, and that cyberbullying victimization uniquely contributes to internalizing problems among Indigenous youth" (ibid.: 7). 
Another study used qualitative data collected through interactions online from Indigenous youth (aged eleven to seventeen) from British Columbia who had taken part in an internet-based mentoring program. The study by Sam, Wisener, Schuitemaker, and Jarvis-Selinger (2018) addressed four themes: technology use, awareness of online safety, experiences of cyberbullying, and prevention and coping skills. Whereas previous studies had focused mainly on Facebook usage, these researchers found Indigenous youth to be using an array of social media and other platforms for educational, networking, and entertainment purposes, including Twitter, Snapchat, YouTube, Instagram, and Tumblr, among others (ibid.). As with other studies in this area, cyberbullying was a prevalent experience among youth, either through direct experience or witnessing the cyberbullying of friends and acquaintances (ibid.). As one participant explained, "we take advantage of it, it gets used for homework, studying or doing such things as e-mentoring, but it's also used to bully and harass people" (ibid.: 14). As was similarly noted in the Lemstra (2011) and Broll (2017) studies, in the Sam et al. (2018) study, participants addressed the negative impacts of cyberbullying on their mental and emotional health. For example, one observed that her experience of cyberbullying "seemed like the worst possible thing that could happen to me," whereas another described the experience as "very stressful" and "downright horrible" (ibid: 14).

Another study examining the experiences of cyberbullying among students used a sample of interviews conducted with university students, faculty, and school administrators at four post-secondary sites. This study drew on data collected from a mixed methodological approach that incorporated online surveys, focus groups, and interviews focused on one's experiences and negative impacts of online bullying (Casidy, Faucher, and Jackson 2017). Unfortunately, the experience of only one Indigenous student is referenced in the paper; however, the negative personal and cultural impacts experienced by this individual are important and worth citing: "one Aboriginal student, who did not supply many details, simply wrote: 'I felt inadequate and I questioned my Status as an Aboriginal'” (ibid.: 8).

The last study in this grouping is an exploratory analysis of rates and experiences of cyberbullying among adult gay and bisexual men drawn from survey data (Lam, Ferlatte, and Salway 2019). One of the key demographic characteristics explicitly examined is Indigenous status, reporting Indigeneity as one of the primary risk factors for cyberbullying among gay and bisexual men (ibid.). Possible explanations cited for this finding include institutional racism, negative stereotypes, and "the erasure of TwoSpirit culture," which they suggest that has resulted in some communities treating 
homosexuality as the same as pedophilia, thus fueling "oppression of Aboriginal sexual minorities" (ibid.: 346).

\section{Responses to Cybervictimization}

We must note that none of the papers included in our sample specifically examined the issue of police or other responses to cybervictimization. Instead, we had to either look for information and recommendations by extracting relevant material from the papers collected on cyberharms or by including sources from which we might make general observations (see Table 3). An example of the latter is Jones and colleagues' (2017) paper on Indigenous policing services, citing that the lack of technology impedes working effectively online. From the little relevant information we could locate, we have grouped responses into four categories: mental health support for victims, personal coping strategies, reporting victimization to police, and reporting victimization to teachers or family members.

Table 3. Papers Focusing on Responses

\begin{tabular}{|l|l|}
\hline Topic & n \\
\hline Reporting to police & 4 \\
\hline Personal coping strategies & 2 \\
\hline Mental health support & 1 \\
\hline Reporting to teachers, family & 1 \\
\hline Total & $\mathbf{8}$ \\
\hline
\end{tabular}

\section{Mental Health Support}

The issue of counseling and other services for victims was raised in one $(n=1)$ paper: the study on cyberbullying of Indigenous children and youth by Broll and colleagues (2017). These scholars suggest that as cyberbullying is associated with adverse health outcomes - principally, as other researchers have observed, anxiety and depression we need to consider developing research into the effective provision of mental health services to ameliorate these outcomes. 


\section{Personal Coping Strategies}

Two $(n=2)$ papers referenced the use of personal coping strategies in response to either direct experience of cyberharms and/or witnessing the victimization of others. The first is Wagner's (2020: 10) study of online harassment of politicians in which she notes that an Indigenous woman, who had observed "vicious online attacks against women politicians," was planning to run for municipal office. Although no details are provided, we are told this participant had "developed a game plan" for how she would react to racism and sexism online (ibid.: 10).

The second study in which personal coping strategies are discussed was in the Sam (2018) study of Indigenous students using an online mentoring program. Some of the strategies students outlined included changing their security settings, deleting accounts, ignoring 'trolls,' and responding calmly (ibid.). As an example, one student stated, "I've won most of the fights because of the ways of handling it. With me, it's talking back, not rudely, but with logic, do it in a calm way, and don't give them anything to use against you" (ibid.: 15).

\section{Police Responses}

Four $(n=4)$ papers referenced police responses, including the option of mobilizing the police in response to victimization. One of these was the Sam (2018) paper in which some students who had been cyberbullied stated they might report certain activities to the police. However, no specific examples were provided.

Two $(n=2)$ of the other papers examined the impacts of moving the trafficking of women and girls into the online environment. One of these was Louie's (2017) study of the use of the online environment to recruit and sexually traffic Indigenous girls. In it, Louie (2017) observes that social media has reduced the ability of police and other intervenors to identify victims of sexual exploitation, as they are no longer visible in the streets and other public places. Boyer and Kampouris (2014) state that as human trafficking has moved online, so too have police. To investigate online sexual exploitation, investigators have to engage in proactive searches for tell-tale signs that someone is being trafficked (ibid.). That said, both the researchers and police interviewees acknowledge that "the Internet presents additional challenges to police services" because the activity can be hidden or obscured, necessitating increased efforts at identifying cases (ibid.: 47).

One significant challenge facing police efforts to respond to cybervictimization of Indigenous citizens is that an unknown volume of such activity occurs in locations with 
a limited police presence or where police are under-resourced. Jones and colleagues' (2017) paper on Indigenous police services is based on interviews with police leaders and a survey of some 800 police officers working in Indigenous communities across Canada. Analysis of these data sources suggests that many communities may lack the infrastructure necessary to respond to cybervictimization. For example, they note a lack of "communication requirements (towers), requirements for consistent internet access and other basic requirements that a police service needs to do its job effectively" (ibid.: 591).

\section{Prevention}

An area in which it is evident that significantly more research is needed is that of prevention, including both innovative and evaluative research of existing cyber-based strategies. Only six $(n=6)$ of the papers discussed the issue of cyber-prevention in any way, and none tested specific strategies or programs to reduce harm. Where prevention was mentioned, it was often in the form of recommendations or quick descriptions of known programs that were either police-led $(n=1)$ or actual or potential educational initiatives led by community groups or school educators $(n=5)$.

\section{Police Prevention Strategies}

The issue of police prevention efforts was raised by Boyer and Kampouris (2014) in their study of the human trafficking of Indigenous women and girls. Drawing on interview data with police and other respondents, they observed that the RCMP had created a public education tool to help increase awareness of human trafficking and the tactics associated with it (ibid.). These 'toolkits' were distributed to Indigenous communities across Canada (ibid.).

\section{Educational Strategies (Schools, Communities, Community Groups)}

By way of contrast, we note that four $(n=4)$ papers raised the issue of community- or school-based prevention initiatives. Unfortunately, we also note that only one $(n=1)$ of these, a paper by Louie (2018) based on his dissertation work on human trafficking, focused exclusively on what prevention of cyberharms could or should look like within Indigenous communities. Nevertheless, drawing on data from qualitative interviews with survivors of sexual exploitation, Louie (2018: 653-654) makes clear-cut recommendations worth quoting at some length:

Sexual exploitation survivors provided profound insight into potential education for youth in critical periods of recruitment. Based on the interviews in this study, 
prevention education should be focused on Indigenous girls from ages seven to 13 years in on-reserve schools. A combination of teachers, survivors, female community members, Elders, role models, and service providers should teach prevention education using love, engagement, patience, availability, and understanding. Entire families should be included in every step and should insist upon local cultural education and ways of knowing whenever possible.

Similar recommendations for prevention are also contained in his earlier paper (Louie 2017), in which he explains why it is vital for cyber-based human trafficking prevention strategies that address the particular dynamics facing Indigenous girls on reserves. It is stressed that children, youth, families, and communities need to be aware of the dangers of social media generally and in relation to Indigenous young people (ibid.). As he says,

The situation for Indigenous girls on reserves creates unique circumstances in which the potential threats are less obvious. Although some non-Indigenousspecific prevention education is relevant for reserve populations, the recruiters using social media in the Indigenous context are more likely to be friends or relatives (ibid.: 105).

Undertaking such prevention work, he suggests, should be educators with extensive community input, and that families should also play a significant role in both learning and facilitating much-needed discussions (ibid.). "Curricula designed for parents, teachers, and school administrators," he notes, "can illuminate the signs of exploitation at the earliest stages, making intervention possible prior to youth becoming fully immersed in exploitation, is needed (ibid.: 106). Turkington (2020) mentions in passing that two of his research participants, who work in the anti-trafficking field in British Columbia, had referenced Internet and app-based prevention tools for children and youth; however, no other details are provided.

In their findings, Lemstra and colleagues (2019) similarly highlight the importance of prevention efforts in reducing cyberbullying. Implementing such efforts in Canada, especially among youth on-reserve who face higher rates of aggression online, they believe, needs to be "a priority" (ibid.: 465). This view is shared by Sam et al. (2018), who, while recognizing that most of their sample of Indigenous students were aware of the need for online safety, may not have consistently recognized the potential harms associated with some common activities. In their words, 
The seeming ubiquity of sharing digital media content (e.g., pictures, texts, videos) online among young Aboriginal people, its link with cyberbullying, and the continued rise in technology use make culturally relevant and developmentally appropriate interventions an urgent matter. Additional research on Aboriginal youth's online experiences is needed to better inform the creation of culturally appropriate educational resources (ibid.: 17).

\section{Conclusions and Recommendations}

We are keenly aware that almost all research reviews include calls for further research. This systematic review will be no different. In the introduction to this review, we laid out one rationale - among many other potential reasons we could provide - as to why the digital cybersecurity divide facing Indigenous communities is an important policy issue. High rates of exposure to certain cyberharms, such as human trafficking and cyberbullying, strengthen the case for making such a call.

Currently, each of these critical subject areas is under-researched. In fact, we could only find one or two papers on any given topic beyond the six located on cyberbullying of Indigenous children and youth. For example, concerning cyberharms, we could locate no research specifically examining Indigenous persons' exposure to and/or experiences of the range of frauds that are so ubiquitous in the online world. Nor could we find any research directly examining either individual, group, law enforcement, or other responses to cyberharms affecting Indigenous communities or on the use of prevention-oriented programs, tools, and resources. We must start to diversify research in this area.

Much of the research literature we reviewed discusses cites Facebook as a site where harm can occur. Today, in 2021, many young people use a host of other sites and apps, including Snapchat, Instagram, and TikTok. None of these, or their unique features and how these features can facilitate cyberharm, are discussed in the literature. Indeed, even older platforms, such as Twitter, are not included.

As Lam and colleagues' (2017) study shows, we need to develop research that treats Indigeneity as more than just a variable or as a monolithic entity or static identity. In other words, we need to consider the various ways in which Indigeneity intersects with class, gender, sexual and other factors to create unique risk pathways.

Both the cyberbullying and human trafficking literature - although small in volume and narrow in scope - raises distinct possibilities that Indigeneity may be an important risk 
factor for certain forms of cybervictimization. This needs to be explored much further in relation to these two forms of cyberharms and others as well.

A recurring sub-theme found in discussions of cyberharms is how online victimization experiences can contribute to feelings of depression, anxiety, self-doubt, and personal and cultural alienation. Less frequently, we also observed some steps - if only in passing - participants in the studies selected have taken to develop their own coping skills and build their own cyber-resiliency. We would encourage policy-makers to develop policy and funding initiatives that support research addressing the mental and emotional harms associated with cyber-victimization, both concerning Indigenous groups and other communities.

Only six $(n=6)$ of the papers raised the issue of cyber-prevention in any way, and none tested specific strategies or programs to reduce the threat of harm. The need for such research, we argue, is particularly acute in relation to human trafficking prevention, as well as that which aims to reduce other cyberharms, such as those identified above. Any such prevention-oriented initiatives should be subjected to rigorous evaluation.

\section{Appendix I: List of Peer-Reviewed, Published Canadian Papers on Indigenous Cybercrime-related Topics (2000-2021).}

Broll, R., Dunlop, C. and Crooks, C. 2018. 'Cyberbullying and Internalizing Difficulties Among Indigenous Adolescents in Canada: Beyond the Effect of Traditional Bullying.' Journal of Child and Adolescent Trauma, 11(1): 71-79.

Cassidy W., Faucher, C. and Jackson, M. 2017. 'Adversity in University: Cyberbullying and Its Impacts on Students, Faculty, and Administrators'. International Journal of Environmental Research and Public Health, 14(8):888-907.

Hill, C. and Johnson, H. 2020. 'Online Interpersonal Victimization as a Mechanism of Social Control of Women: An Empirical Examination.' Violence Against Women, 26(1213):1681-1700.

Kiedrowski, J., Jones, N. and Ruddell, R. 2017. 'Set Up to Fail?' An Analysis of SelfAdministered Indigenous Police Services in Canada.' Police Practice and Research, 18(6): 584-598.

Lam, S., Ferlatte, O., and Salway, T. 2019. 'Cyberbullying and Health: A Preliminary Investigation Of the Experiences Of Canadian Gay And Bisexual Adult Men.' Journal of 
Gay \& Lesbian Social Services, 31:3, 332-357.

Lemstra, M., Rogers, M., Redgate, L., Garner, M. and Moraros, J. 2011. 'Prevalence, Risk Indicators and Outcomes of Bullying Among On-Reserve First Nations Youth.' Canadian Journal of Public Health, 102(6), 462-466.

Louie, D. 2018. 'Sexual Exploitation Prevention Education for Indigenous Girls.' Canadian Journal of Education / Revue Canadienne de l'Education, 41(2): 633-663.

Louie, D. 2017. 'Social Media and the Sexual Exploitation of Indigenous Girls.' Girlhood Studies, 10(2): 97-113.

Mobin, A., Feng, C. and Neudorf, C. 2018. 'Cybervictimization Among Preadolescents In A Community-Based Sample In Canada: Prevalence And Predictors.' Canadian Journal of Public Health, 108(5-6): e475-e481.

Sam, J., Wisener, K., Schuitemaker, N. and Jarvis-Selinger, S. 2018. 'Aboriginal Youth Experiences with Cyberbullying: A Qualitative Analysis of Aboriginal e-Mentoring.' International Journal of Indigenous Health, 13(1): 5 - 19.

Wagner, A. 2020. 'Tolerating the Trolls? Gendered Perceptions of Online Harassment Of Politicians In Canada.' Feminist Media Studies. Online first.

\section{Appendix II: List of Grey Literature on Indigenous Cybercrime Topics (2001-2021).}

Boyer, Y. and Kampouris, P. 2014. 'Trafficking of Aboriginal Women and Girls.' Report for Public Safety Canada. Available at: https://publications.gc.ca/site/archiveearchived.html?url=https://publications.gc.ca/collections/collection_2015/sp-ps/PS18-82014-eng.pdf.

Turkington, D. 2020. 'Human Trafficking of Indigenous Women and Girls in Canada: A Review of State and NGO Prevention Efforts.' University of Victoria, MA Thesis.

\section{References}

Ali-Hassan, H., Eloulabi, R. and Keethakumar, A. 2020. 'Internet Non-Use Among Canadian Indigenous Older Adults: Aboriginal Peoples Survey (APS).' BMC Public 
Health. Online first.

Andrey, S., Massodi, M., Malli, N., and Dorkenoo, S. 2021. 'Mapping Toronto's Digital Divide.' Brookfield Institute report. Available at: https://brookfieldinstitute.ca/wpcontent/uploads/TorontoDigitalDivide_Report_Feb2021.pdf

Debb, S., Schaffer, D., and Colson, D. 2020. 'A reverse digital divide: comparing information security behaviours of generation $\mathrm{Y}$ and generation $\mathrm{Z}$ adults.' International Journal of Cybersecurity Intelligence and Cybercrime, 3(1): 42-55.

Beaton, B., Burnard, T. and Linden, A. 2015. 'Keewaytinook Mobile: An Indigenous Community-Owned Mobile Phone Service in Northern Canada', in Dyson, L., Grant, S. and Hendricks, M. (eds.) Indigenous People and Mobile Technologies. New York: Routledge. Pp. 109-124.

Canadian Radio-television and Telecommunications Commission (CRTC). 2019. 'Communications Monitoring Report.' Available at: https://crtc.gc.ca/eng/publications/reports/policymonitoring/2019/cmr9.htm

Gaertner, D. 2015. 'Indigenous in Cyberspace: CyberPowWow, God's Lake Narrows, and the Contours of Online Indigenous Territory .' American Indian Culture and Research Journal, 39(4): 55-78.

Hamel, C., Benyoucef, M. and Kuziemsky, C. 2012. 'Determinants of participation in an Inuit online community of practice.' Knowledge Management Research \& Practice, 10(1): 41-54.

Holt, T. and Bossler, A. 2008. 'Examining the Applicability of Lifestyle-Routine Activities Theory for Cybercrime Victimization.' Deviant Behavior, 30(1): 1-25.

Howard, P., Busch, L. and Sheets, P. 2010. 'Comparing Digital Divides: Internet Access and Social Inequality in Canada and the United States.' Canadian Journal of Communication, 35(1): 109-128.

Jongbloed, K., Pearce M., Thomas, V., Sharma, R., Pooyak, S., Demerais, L., Lester, R., Schechter, M., Spittal, P., and The Cedar Project Partnership. 2020. 'The Cedar Project - Mobile Phone Use and Acceptability of Mobile Health Among Young Indigenous People Who Have Used Drugs in British Columbia, Canada: Mixed Methods Exploratory Study.' JMIR Mhealth and Uhealth, 8(7):e16783. Published online. 
Kimery, K. and Amirkhalkhali, S. 2011. 'Information And Communication Technologies and Aboriginal Peoples in Canada: Information Seeking, Community Building, And Access Challenges In Geographically and Socially Marginalized Populations.' International Journal of Management \& Information Systems, 15(4).

McMahon, R. 2011. 'The Institutional Development of Indigenous Broadband Infrastructure in Canada and the United States: Two Paths to "Digital SelfDetermination"'. Canadian Journal of Communication, 36(1): 115-140.

O’Donnell, S., Kakekaspan, G., Beaton, B., Walmark, B., Mason, R., and Mak, M. 2011. 'A New Remote Community-Owned Wireless Communication Service: Fort Severn First Nation Builds Their Local Cellular System with Keewaytinook Mobile.' Canadian Journal of Communication, 36(4), 663-673.

Powell, A. and Henry, N. 2019. 'Technology-Facilitated Sexual Violence Victimization: Results From an Online Survey of Australian Adults.' Journal of Interpersonal Violence, 34(17):3637-3665.

Rogers, S. 2017. 'Nunavik to get cellular service in 2018.' Nunatsiaq News. Available at: http://nunatsiaq.com/stories/article/65674nunavik_to_get_cellular_service_in_2018/.

Staksrud, E., Ólafsson, K. and Livongstone, S. 2013. 'Does the Use of Social Networking Sites Increase Children's Risk of Harm?' Computers in Human Behavior, 29 (1): 40-50.

Toth, K., Smith, K., and Giroux, D. 2018. 'Indigenous Peoples and Empowerment via Technology', First Peoples Child \& Family Review, 13(1): 21-33.

Whitty, M. 2020. 'Is There a Scam for Everyone? Psychologically Profiling Cyberscam Victims.' European Journal on Criminal Policy and Research, 26(3), 399-409.

Xiao, Y. and Watson, M. 2019. 'Guidance on Conducting a Systematic Literature Review.' Journal of Planning Education and Research, 39(1): 93-112.

\section{Footnotes}

1. Some of the papers we collected used the term 'online harassment' concerning adults; others used 'cyberbullying.' For the sake of consistency, we use 'online harassment' when the author(s) have done so, and 'cyberbullying' when they have, again, chosen to use that term. 
2. The focus of one paper in our collection was on Indigenous policing rather than on cyber-victimization; thus, our total number here is twelve $(n=12)$ rather than thirteen. $\subseteq$ 